\title{
Images
}

\section{More than a laceration: a case of pneumocephalus}

\author{
Layli Sanaee, MD*; Hans Rosenberg, MD*
}

A 52-year-old female presented to the emergency department with a forehead laceration after an unwitnessed fall. She reported feeling lightheaded after getting out of bed and then falling forward from a standing position, striking the tile floor. She denied loss of consciousness, amnesia, vomiting, or seizure activity. She reported epistaxis but denied otorrhea. She reported a fall 1 week previously but did not recall the circumstances and did not seek medical care.

Her past medical history included an ileostomy and depression. She denied any new medications.

On examination, the patient was alert and oriented. Her vital signs were within normal limits. There was a $10 \mathrm{~cm}$ laceration on the right side of the forehead, exposing the frontalis muscle. The neurologic examination was unremarkable, with no neurologic deficits. There were no signs of a basal skull fracture and no tenderness on palpation of the facial bones, sinuses, or nose. Ecchymosis on her right lower back was attributed to her previous fall.

Owing to the mechanism of injury, computed tomography of the head with facial bone views was obtained, which showed extensive pneumocephalus (Figure 1) but no midline shift or signs of tension. Undisplaced fractures of the medial wall of the right orbit and posterior wall of the frontal sinus were identified. The patient was admitted to Neurosurgery and conservatively managed. She was discharged home after 3 days with no significant sequelae.

Competing interests: None declared.

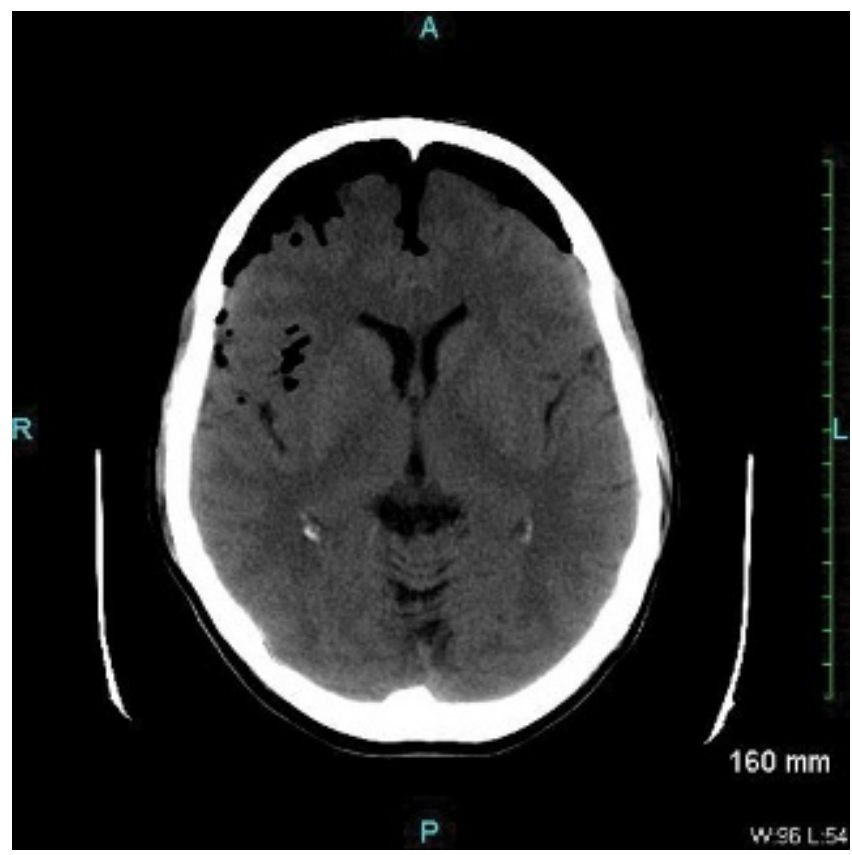

Figure 1. Computed tomography of the head of a 52-year-old woman who struck her head after falling from standing height onto a tile floor.

From the *Department of Emergency Medicine, The Ottawa Hospital, Ottawa, ON.

Correspondence to: Dr. Layli Sanaee, Department of Emergency Medicine, The Ottawa Hospital - Civic Campus, 1053 Carling Avenue, E-Main, Room EM-206, Box 227, Ottawa, ON K1Y 4E9; layli.sanaee@medportal.ca.

Submitted September 22, 2010; Accepted November 1, 2010.

This article has been peer reviewed. 